\title{
Correction to: Genetic Basis of Oral Health Conditions
}

\section{Correction to: A. R. Vieira, Genetic Basis of Oral Health Conditions, https://doi.org/10.1007/978-3-030-14485-2}

Figures 1.1, 6.2 and 7.2 were published with errors in the original version and have now been corrected.

The updated online version of these chapters can be found at https://doi.org/10.1007/978-3-030-14485-2_1 https://doi.org/10.1007/978-3-030-14485-2_6 https://doi.org/10.1007/978-3-030-14485-2_7 
Fig. 1.1 A complex or COMPLEX multifactorial inheritance model is the one caused by more than one gene, each having a relatively small effect. These effects can be additive and they can be influenced by environmental factors. A single gene model is determined by a major gene effect, which can be dominant or recessive, depending if one copy or two is needed of an altered allele to express the phenotype. This expression can vary from individual to individual even within the same family, and this variation can be understood as modulated by other genes and/or modified by the environment

\section{COMPLEX}

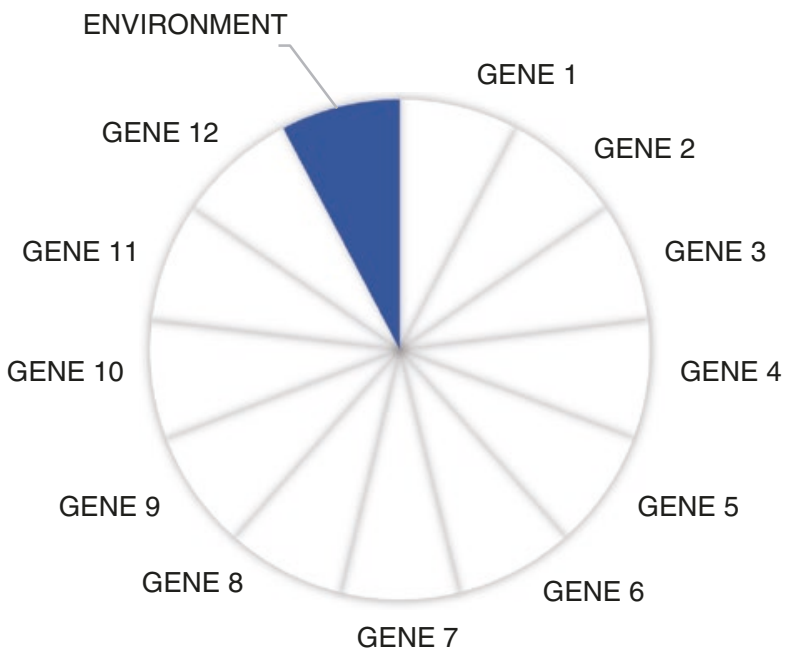

SINGLE GENE

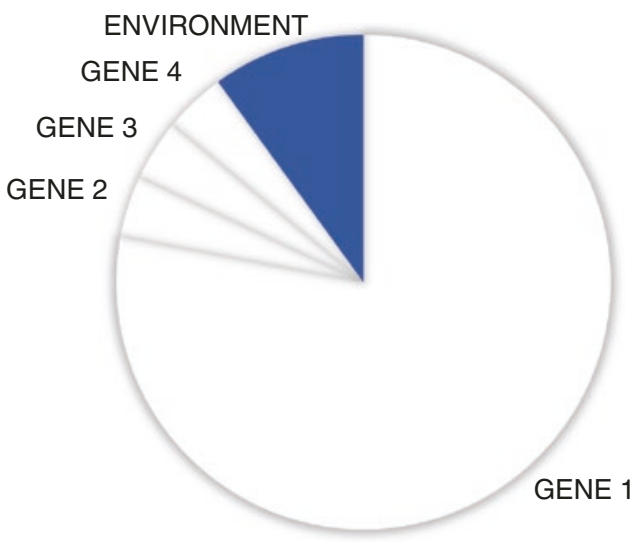


Fig.6.2 Alveolar width change post-extraction varies greatly among people (Bars indicate means and lines standard deviations. (1) Barone et al. 2008; (2) Camargo et al. 2000; (3) Iasella et al. 2003; (4) Lekovic et al. 1997; (5) Lekovic et al. 1998; (6) Serino et al. 2003)

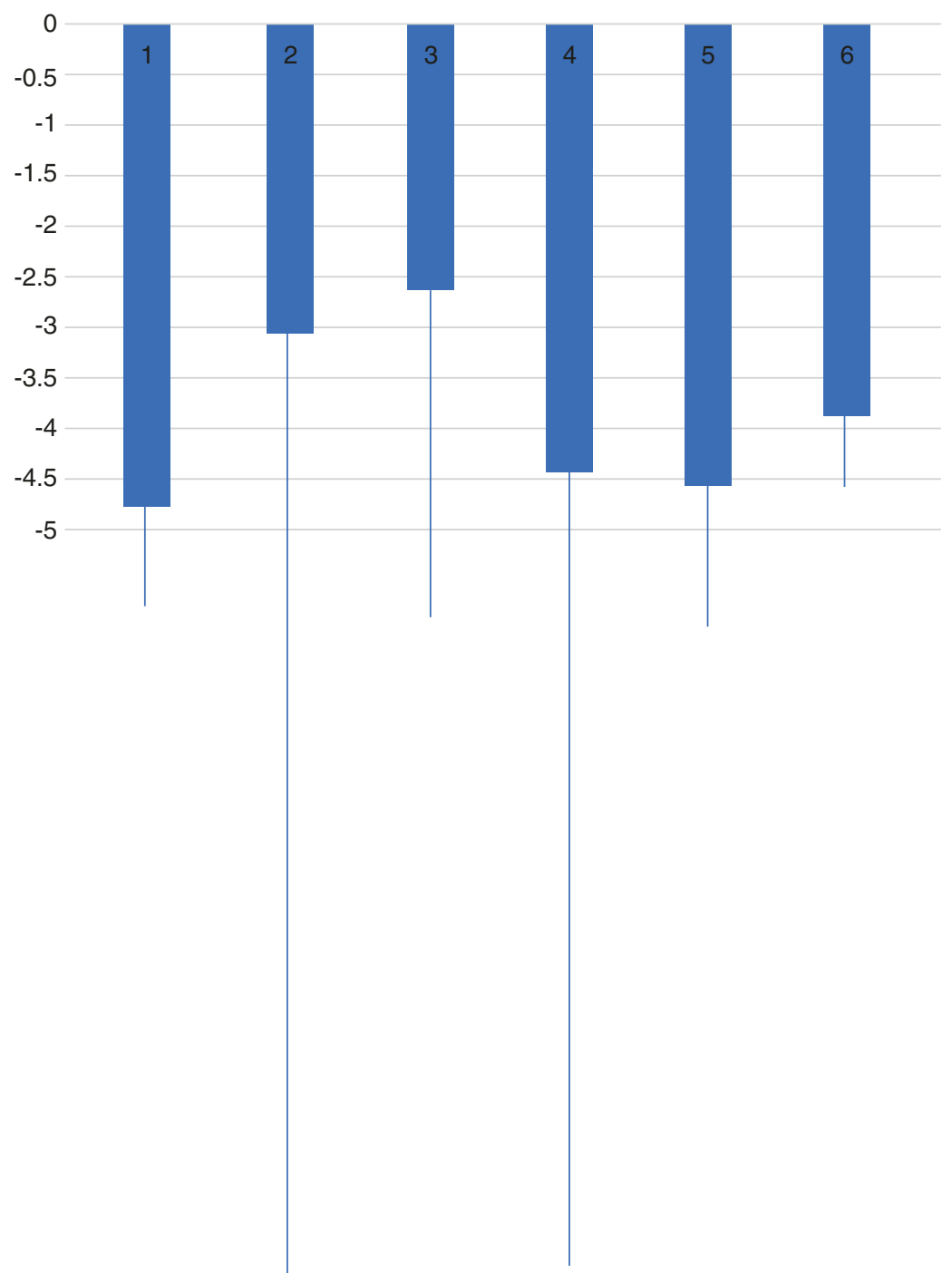


$\square \mathrm{RR} \square \mathrm{RX} \square \mathrm{XX}$

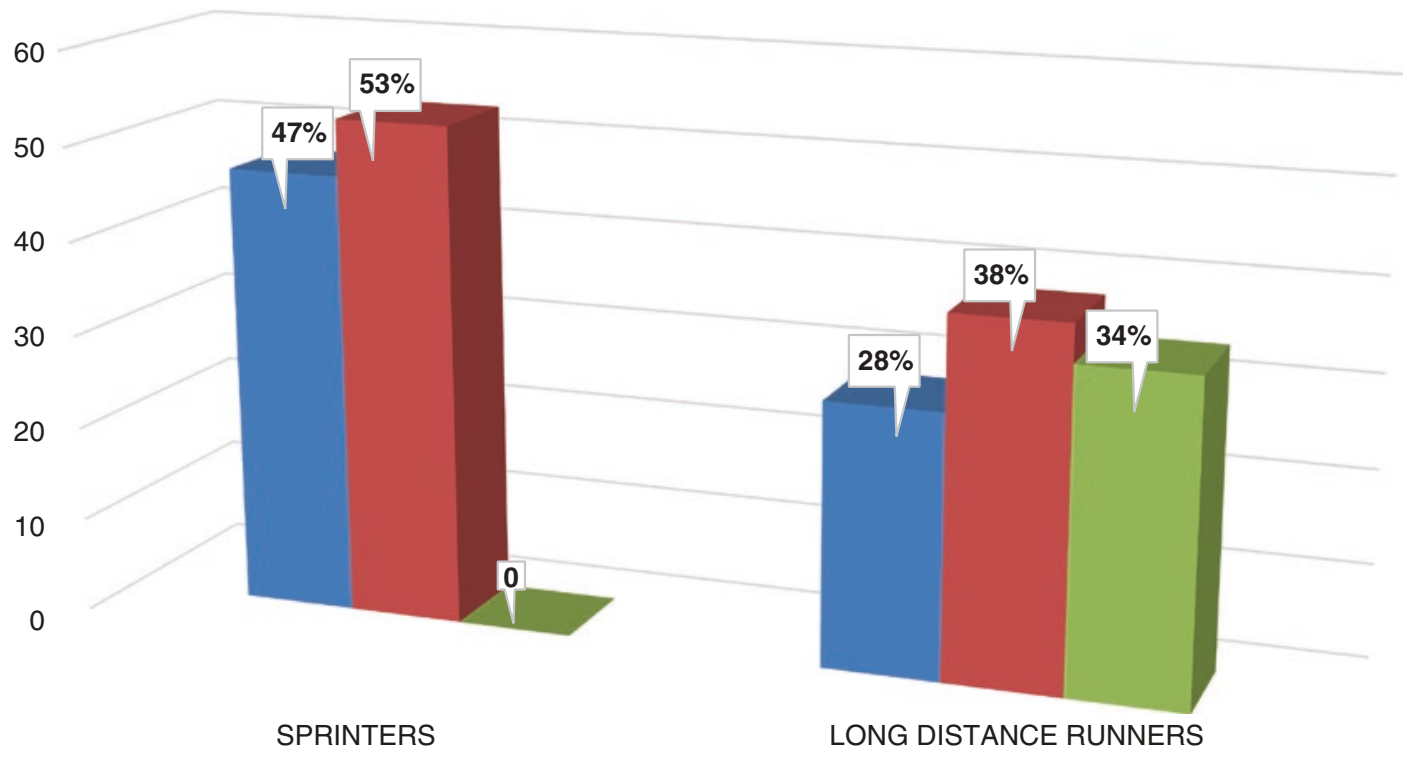

Fig. 7.2 Frequency of ACTN3 R577X genotypes in track and field Olympic athletes who are sprinters versus longdistance runners (Yang et al. 2003). The XX genotype is more common in long-distance runners. The frequency of

$\mathrm{X}$ is also more common in Class II individuals and less common in individuals with a deep bite (Zebrick et al. 2014) 